\title{
Polymer Light-Emitting Diodes Based on PPDFV Copolymers with Fluoro Groups in Vinylene Units
}

\author{
Youngeup Jin, Jinwoo Kim, Suhee Song, Sung Heum Park, ${ }^{\dagger}$ Kwanghee Lee, ${ }^{\dagger}$ and Hongsuk Suh ${ }^{*}$ \\ Department of Chemistry and Center for Plastic Information System, Pusan National University, Busan 609-735, Korea \\ *E-mail: hssuh@pusan.ac.kr \\ ${ }^{\dagger}$ Department of Physics and Center for Plastic Information System, Pusan National University, Busan 609-735, Korea \\ Received February 2, 2005
}

Key Words : Electroluminescence, PPV, Polymer, PLED, Light-emitting diodes (LEDs)

Organic light emitting diodes (OLEDs) have attracted much interest because of their particular low driving voltage, convenient design of the device structures, possible control of emission band, and low fabrication cost compared with any other devices. ${ }^{1-3}$ Since the discovery of electroluminescence (EL) from a conjugated polymer, main-chain conducting polymers such as poly(plenylene vinylene) (PPV), poly( $p$-phenylene) (PPP), their copolymers and soluble derivatives, has been studied intensively for the possible application as large-area light emitting diodes (LEDs). ${ }^{4-6}$ However, PPV has the disadvantage that electron injection is much more difficult than hole injection. Using additional organic charge-transporting layers, ${ }^{7-9}$ and adjusting the energy band of the polymer by introduction of electronwithdrawing groups attached to the polymer backbone were reported to overcome the imbalance of charge carrier injection or mobility. The introduction of electron-withdrawing groups onto the arylene rings or the vinyl groups of PPV lowers the HOMO and LUMO energy levels of the polymer, thereby permitting the use of a higher work function metal in the LED device. ${ }^{10}$ Numerous derivatives of PPV have been reported with electron-withdrawing substituents such as halide, ${ }^{11-15}$ cyano, ${ }^{16,17}$ trifluoromethyl, ${ }^{18}$ or methylsulfonylphenyl $^{19}$ on the arylene rings. In our previous work, ${ }^{20}$ we reported poly ( $p$-phenylenedifluorovinylene) (PPDFV) and poly(2-dimethyloctylsilyl-p-phenylenedifluorovinylene) (DMOS-PPDFV) with fluoro groups as electron withdrawing substituents on vinylene units of conjugated polymers, which showed the high performance of OLEDs. In the present paper, we report the synthesis and electroluminescent properties of the copolymers with $p$-phenylenedifluorovinylene and 2-dimethyloctylsilyl-p-phenylenevinylene units. The resulting EL polymers were synthesized by the Gilch polymerization method. ${ }^{21}$

\section{Experimental Section}

The general synthetic routes toward the monomers and polymers are outlined in Scheme 1. In the first step, $p$-xylene (1) was brominated using $N$-bromosuccinimide (NBS) and light source $(300 \mathrm{~W})$ to generate $\alpha, \alpha$-dibromo- $p$-xylene (2). ${ }^{22(a)}$ The resulting dibromide was fluorinated $(3)^{22(b)}$ with tetrabutylammonium fluoride (TBAF), then brominated again using NBS and light source to generate 1,4-bis(bromofluoromethyl)benzene (4), ${ }^{22(c)}$ the monomer for PPDFV. The other monomer was synthesized in two steps. 2-Bromo- $p$ xylene (5), as the starting material, was coupled with chlorodimethyloctylsilane (6) using n-butyllithium in THF to generate dimethyloctylsilyl- $p$-xylene (7). ${ }^{22(\mathrm{~d})}$ Compound 7 was brominated, using $N$-bromosuccinimide (NBS) and

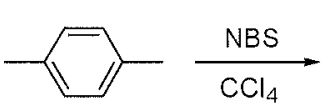

(1)

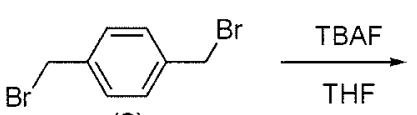

(2)

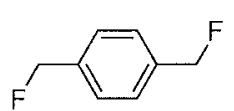

(3)
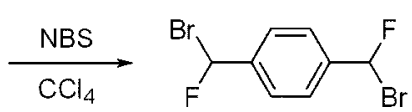

(4)

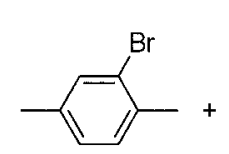

(5)

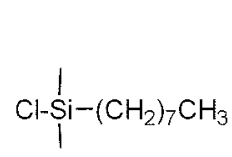

(6)

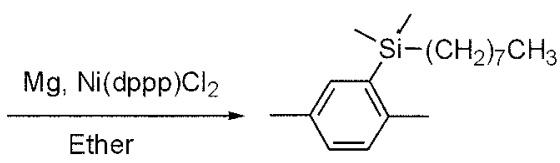

(7)

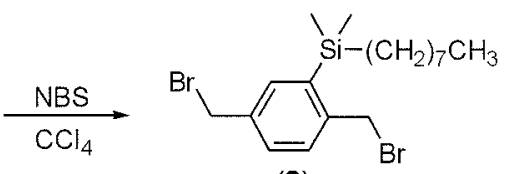

(8)

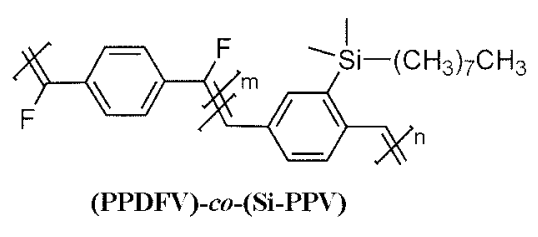

Scheme 1. Synthetic Routes for Monomer and Polymers. 
Table 1. Polymerization Results of PPDFV-co-DMOS-PPVs

\begin{tabular}{ccrrr}
\hline Composition ratio $^{a}$ & $\begin{array}{c}\text { feed ratio } \\
\mathbf{( 4 : 8 )}\end{array}$ & $\mathbf{M}_{\mathrm{n}}{ }^{b}$ & $\mathrm{M}_{\mathrm{w}}{ }^{b}$ & PDI $^{b}$ \\
\hline $15: 85$ & $1: 9$ & 37,400 & 106,800 & 2.8 \\
$23: 77$ & $3: 7$ & 29,000 & 65,700 & 2.3 \\
$36: 64$ & $5: 5$ & 19,700 & 41,600 & 2.1 \\
$42: 58$ & $7: 3$ & 16,800 & 29,200 & 1.7 \\
$92: 8$ & $9: 1$ & 10,600 & 21,800 & 1.6 \\
\hline
\end{tabular}

${ }^{a}$ The composition ratios of the copolymers were determined from the comparison of the peaks of vinylic protons and aromatic protons of PPDFV and DMOS-PPV and dimethyl protons of DMOS-PPV. ${ }^{b} M_{n}$, $M_{w}$, and PDI of the polymers were determined by gel permeation chromatography using polystyrene standards.

light source $(300 \mathrm{~W})$, to generate 1,4-bis(bromomethyl)-2dimethyloctylsilylbenzene $(\mathbf{8}),{ }^{22(\mathrm{e})}$ the monomer for DMOSPPV. The structure and purity of the monomers were confirmed by ${ }^{1} \mathrm{H}-\mathrm{NMR}$, and ${ }^{13} \mathrm{C}-\mathrm{NMR}$. The polymers from these monomers were prepared by the Gilch reaction, ${ }^{21}$ with an excess amount of potassium tert-butoxide in THF at $0{ }^{\circ} \mathrm{C}$ for $24 \mathrm{~h}$ under Ar atmosphere. The copolymerization of the 1,4-bis(bromofluoromethyl)benzene (4) with various feed ratios of 1,4-bis(bromomethyl)-2-dimethyloctylsilylbenzene (8) generated PPDFV-co-DMOS-PPVs which were soluble in various organic solvents such as chloroform, chlorobenzene, THF, dichloromethane and $o$-dichlorobenzene (ODCB). The composition ratios of the copolymers were determined from the comparison of the peaks of vinylic protons and aromatic protons of PPDFV and DMOS-PPV and dimethyl protons of DMOS-PPV. The difference of the feed ratios and the composition ratios was possibly caused by the higher reactivity of monomer 8 as compared to that of monomer 4 . The number-average molecular weight $\left(M_{n}\right)$ and the weightaverage molecular weight $\left(M_{w}\right)$ of copolymers were 10,600 37,400 , and $21,800-106,800$ with polydispersity of $1.6-2.8$ as determined by GPC using THF as the eluent. With higher feed ratio of momoner $\mathbf{8}$, the copolymers have higher molecular weights, which is also caused by the higher reactivity of monomer 8 as compared to that of monomer 4 .

\section{Results and Discussion}

The UV-vis absorption spectra and photoluminescence spectra of PPDFV-co-DMOS-PPVs as thin films are shown in Figure 1 and Figure 2. The thin films were prepared by spin-coating on quartz plates from the polymer solutions with ODCB. The PPDFV-co-DMOS-PPVs exhibit absorption spectra with maximum peaks of 380-425 nm attributed to $\pi-\pi^{*}$ transitions of the conjugated backbones. The maximum absorption peak at $380 \mathrm{~nm}$ was red shifted with more amount of the DMOS-PPV. The absorption onset wavelengths of PPDFV-co-DMOS-PPVs were $502-530 \mathrm{~nm}$, which correspond to band gaps of 2.47-2.34 eV. The PL spectrum of PPDFV-co-DMOS-PPVs (92:8) showed similar single band like that of PPDFV. The PL spectra of other copolymers consist of a typical vibronically structured band comprising a maximum, a shoulder, and a tail which

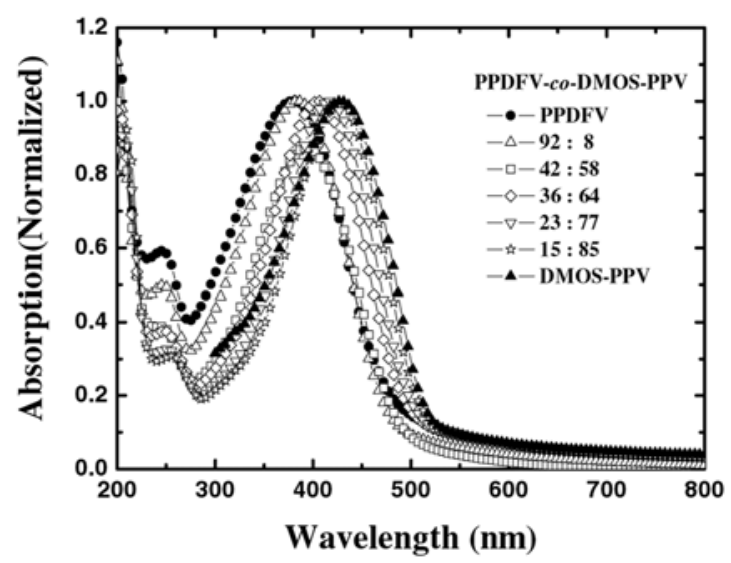

Figure 1. UV-vis absorption spectra of copolymers.

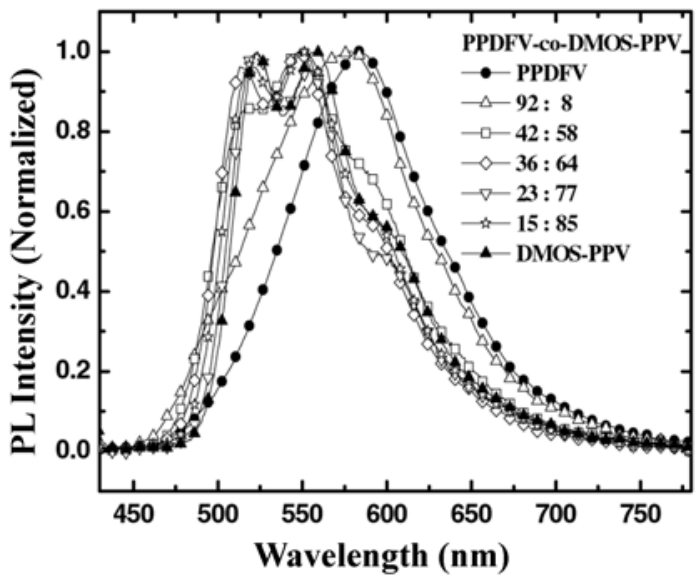

Figure 2. Photoluminescence spectra of copolymers in the solid state.

are similar to those of DMOS-PPV. The similarity of the PL spectra of the copolymers is caused by the highly incorporated DMOS-PPV units in the copolymers. The PL spectrum of the PPDFV thin film exhibits a maximum peak at $584 \mathrm{~nm}$, which were blue-shifted to around $550 \mathrm{~nm}$ with more amount of DMOS-PPV contents of the copolymers. The blue-shift indicates the decrease of the effective conjugation length by the inclusion of the dimethyloctylsilyl group on the arylene unit.

The normalized electroluminescence (EL) spectra and the current-voltage characteristics of the ITO/PEDOT/polymers/ Al device were measured. The PEDOT: PSS was spincoated from aqueous solution with isopropyl alcohol (10 $w t \%)$ on the surface-treated ITO substrate. On top of the PEDOT layer, the emissive polymer film was obtained by spin-casting an ODCB solution of the polymer. The emissive polymer thin film prepared had a uniform surface with a thickness of around $110 \mathrm{~nm}$. The emissive film was dried in vacuum, and the aluminum electrode were deposited on the top of the polymer film through a mask by vacuum evaporation at pressure below about $10^{-6} \mathrm{mbar}$, yielding an active area of $4 \mathrm{~mm}^{2}$. The current-voltageluminescence $(J-V-L)$ characteristics were measured using a Keithley 236 Source Measure Unit. All processing steps and 


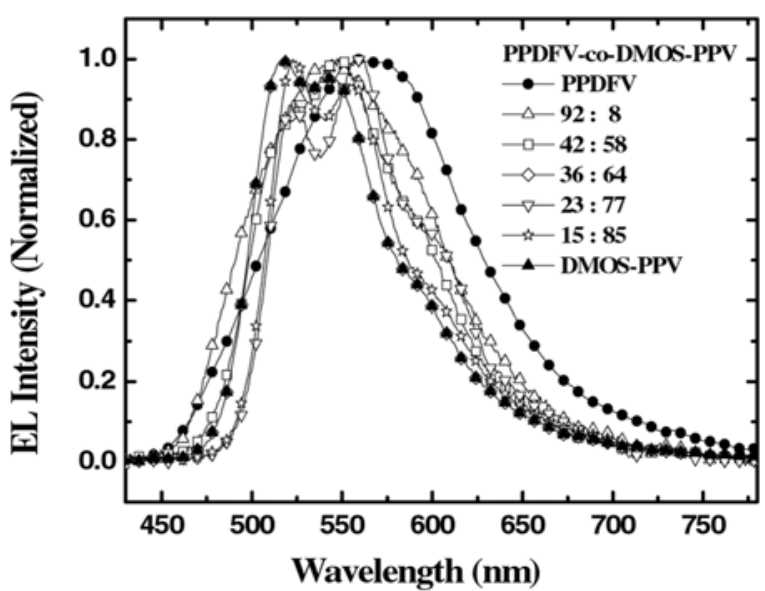

Figure 3. Electroluminescence spectra of copolymers in the solid state.

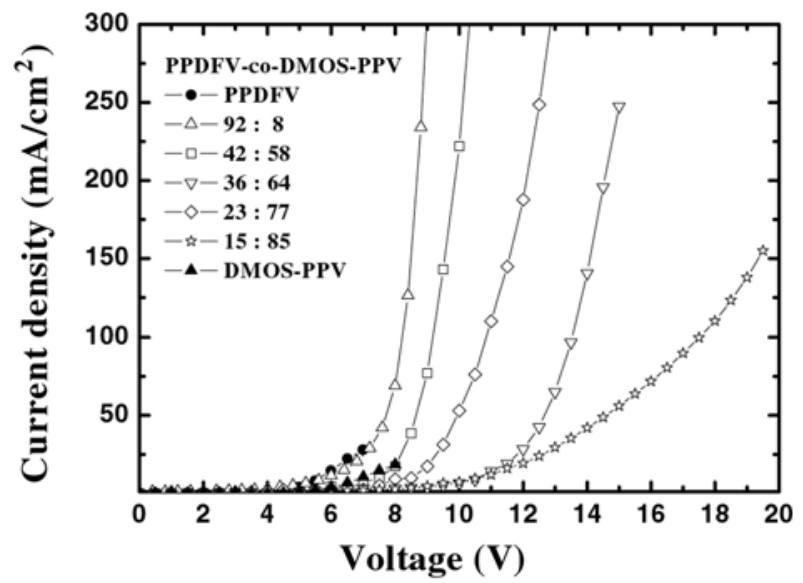

Figure 4. Current density-voltage $(J-V)$ characteristics of ITO/ PEDOT/polymer/Al devices.

measurements mentioned above were carried out under air and at room temperature. Figure 3 shows the normalized EL spectra of ITO/PEDOT/polymer/Al devices. All EL spectra of PPDFV-co-DMOS-PPVs are similar to that of DMOSPPV. The EL spectra of all PPDFV-co-DMOS-PPVs exhibit the maximum peaks at around $550 \mathrm{~nm}$, which correspond to green light.

The current density-voltage-luminescence $(J-V-L)$ characteristics of the devices fabricated from PPDFV-co-DMOSPPVs are shown in Figure 4, and Figure 5. The LUMO energy level of DMOS-PPV is $2.70 \mathrm{eV}$, whereas the level for PPDFV is $3.05 \mathrm{eV}^{20}$ As the PPDFV content in the copolymers is increased, the turn-on voltages of the copolymers are decreased, because the higher work function of the LUMO of PPDFV makes the electron injection process easier as compared to the case of DMOS-PPV. The maximum current densities of the homopolymers, PPDFV and DMOS-PPV, are only 30 and $20 \mathrm{~mA} / \mathrm{cm}^{2}$, respectively. In addition to this, the maximum brightnesses of the homopolymers, PPDFV and DMOS-PPV, are also only about 100 and $70 \mathrm{~cd} / \mathrm{m}^{2}$, respectively. The low maximum current densities and brightnesses of the homopolymers are believed to be caused

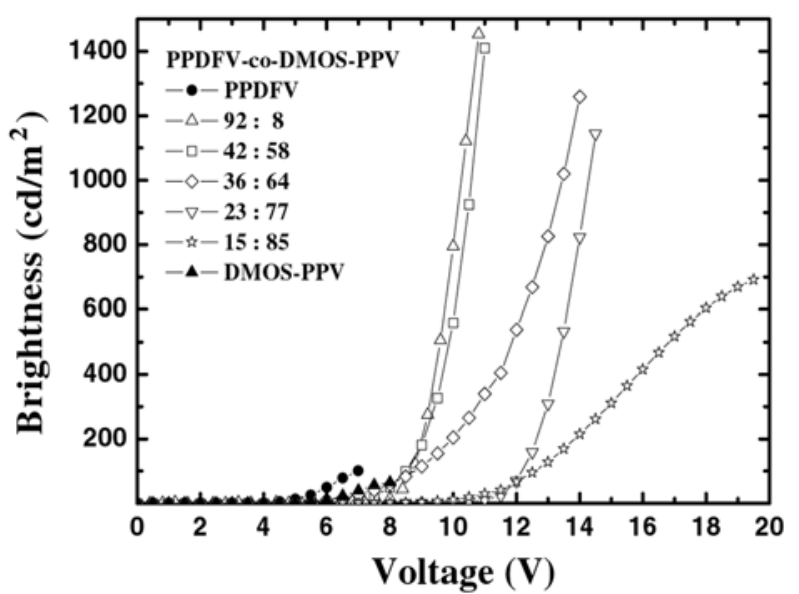

Figure 5. Luminescence-voltage $(L-V)$ characteristics of ITO/ $\mathrm{PEDOT} /$ polymer/Al devices.

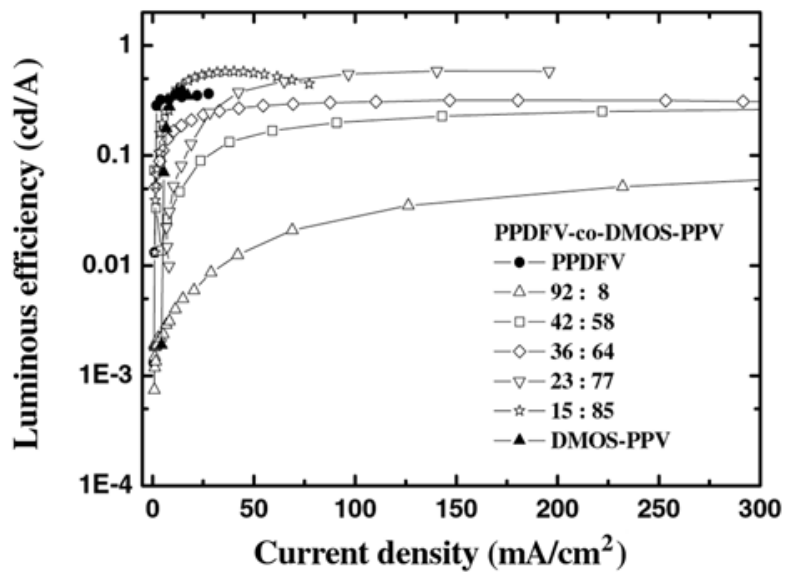

Figure 6. Efficiencies of PLEDs with a configuration of ITO/ PEDOT/polymer/Al.

by the poor morphologies of the films of the homopolymers. In contrast to this, the copolymers showed significantly increased current densities and brightnesses as shown in Figure 4, and 5. The brightnesses of the devices at the same voltage were increasing with higher contents of PPDFV in the copolymers, as shown in Figure 5. At $10.7 \mathrm{~V}$, the copolymers with $92: 8,42: 58$, and $36: 64$ ratios of PPDFV and DMOS-PPV showed the brightnesses of 1450, 1200, $300 \mathrm{~cd} / \mathrm{m}^{2}$. At the same voltage, the copolymers with $23: 87,15: 85$ ratios of PPDFV and DMOS-PPV showed the brightnesses of lower than $50 \mathrm{~cd} / \mathrm{m}^{2}$. The efficiencies of the PLEDs, with a configuration of ITO/PEDOT/polymer/ $\mathrm{Al}$, are shown in Figure 6. The copolymer with $15: 85$ ratio of PPDFV and DMOS-PPV showed highest efficiency, about $0.6 \mathrm{~cd} / \mathrm{A}$ at $40 \mathrm{~mA} / \mathrm{cm}^{2}$.

In conclusion, we have synthesized, by the Gilch reactions, new PPV derivatives as copolymers of $p$-phenylenedifluorovinylene, with fluoro groups in vinylene units, and 2dimethyloctylsilyl-1,4-phenylene-vinylene. The prepared PPDFV-co-DMOS-PPVs exhibit absorption spectra with maximum peaks at $380-425 \mathrm{~nm}$. The PL spectra of the copolymers are similar to that of DMOS-PPV except the 
copolymer with $92: 8$ ratio of PPDFV and DMOS-PPV. The polymer LEDs of PPDFV-co-DMOS-PPVs emit bright green light with maximum peak around $550 \mathrm{~nm}$, which are similar to that of DMOS-PPV, in the device with the configuration of ITO/PEDOT/polymers/Al. As the PPDFV content is increased, the turn-on voltages of the copolymers are decreased from $10 \mathrm{~V}$ to $6 \mathrm{~V}$. The copolymers showed significantly increased current densities and brightnesses as compared to the homopolymers, PPDFV and DMOS-PPV.

Acknowledgements. This work was supported by the Ministry of Information \& Communication, Korea, under the Information Technology Research Center (ITRC) Support Program.

\section{References}

1. Tang, C. W.; Van Slyke, S. A. Appl. Phys. Lett. 1982, 51, 21.

2. Braun, D.; Heeger, A. J. Appl. Phys. Lett. 1991, 58, 1982.

3. Gustaffsson, G.; Cao, Y.; Tracy, M.; Klavetter, F.; Colaneri, N.; Heeger, A. J. Nature 1992, 375, 477.

4. Kraft, A.; Grimsdale, A. C.; Holmes, A. B. Angew. Chem., Int. Ed. 1998, 37, 402.

5. Friend, R. H.; Gymer, R. W.; Holmes, A. B.; Burroughes, J. H.; Marks, R. N.; Taliani, C.; Bradley, D. D. C.; Santos, D. A.; Bredas, J. L.; Lõgdlund, M.; Salameck, W. R. Nature (London) 1999, 357, 121

6. Shim, H. K.; Jin, J. I. Adv. Polym. Sci. 2002, 158, 194.

7. Greenham, N. C.; Moratti, S. C.; Bradley, D. D. C.; Friend, R. H.; Holmes, A. B. Nature (London) 1993, 365, 628.

8. Brown, A. R.; Bradley, D. D. C.; Burroughes, J. H.; Friend, R. H.; Greenman, N. C.; Burn, P. L.; Holmes, A. B. Appl. Phys. Lett. 1992, 61, 2793.

9. Burn, P. L.; Grice, A. W.; Jajbakhsh, A.; Bradley, D. D. C.; Thomas, A. C. Adv. Mater. 1997, 9, 1171.

10. Jin, J. I.; Kim, J. C.; Shim, H. K. Macromolecules 1992, 25,
5519.

11. Bredas, J. L.; Heeger, A. J. Chem. Phys. Lett. 1994, 54, 401

12. Sarnecki, G. J.; Friend, R. H.; Moratti, S. C. Synth. Met. 1995, 69, 545.

13. Gurge, R. M.; Sarker, A.; Laht, P. M.; Hu, B.; Karasz, F. E. Macromolecules 1996, 29, 4287.

14. Gurge, R. M.; Sarker, A.; Laht, P. M.; Hu, B.; Karasz, F. E. Macromolecules 1997, 30, 8286

15. Benjamin, I.; Faraggi, E. Z.; Avny, Y.; Davidov, D.; Neumann, R. Chem. Mater. 1996, 8, 352.

16. Lahti, P. M.; Sarker, A.; Garay, R. O.; Lenz, R. W.; Karasz, F. E. Polymer 1994, 35, 1312.

17. Jin, Y.; Ju, J.; Kim, J.; Lee, S.; Kim, J. Y.; Park, S. H.; Son, S. M.; Jin, S. H.; Lee, K.; Suh, H. Macromolecules 2003, 36, 6970.

18. Grimsdale, A. C.; Cacialli, F.; Gruner, J.; Lix. C.; Holmes, A. B.; Moratti, S. C.; Friend, R. H. Synth. Met. 1996, 76, 165.

19. Boardman, F. H.; Grice, A. W.; Ruther, M. G.; Sheldon, T. J.; Bradley, D. D. C.; Burn, P. L. Macromolecules 1999, 32, 111.

20. Jin, Y.; Kim, J.; Lee, S.; Kim, J. Y.; Park, S. H.; Lee, K.; Suh, H. Macromolecules 2004, 37, 6711.

21. Becker, H.; Spreitzer, H.; Inbrom, K.; Kreuder, W. Macromolecules 1999, 32, 4925.

22. (a) $\alpha, \alpha^{\prime}$-Dibromo- $p$-xylene (2). $R_{f} 0.25\left(\mathrm{SiO}_{2}, \mathrm{Hexane} 100 \%\right) .{ }^{1} \mathrm{H}-$ NMR $\left(200 \mathrm{MHz}, \mathrm{CDCl}_{3}\right) \delta(\mathrm{ppm}) 4.48(\mathrm{~s}, 4 \mathrm{H}), 7.37(\mathrm{~s}, 4 \mathrm{H})(\mathrm{b})$ $\alpha, \alpha$-Difluoro- $p$-xylene (3). $R_{f} 0.28\left(\mathrm{SiO}_{2}\right.$, Hexane $\left.100 \%\right) .{ }^{1} \mathrm{H}-$ NMR (200 MHz, Acetone-d $\left.)_{6}\right) \delta(\mathrm{ppm}) 5.43(\mathrm{~d}, 4 \mathrm{H}, J=49.4 \mathrm{~Hz})$, $7.47(\mathrm{~s}, 4 \mathrm{H}) .{ }^{13} \mathrm{C}-\mathrm{NMR}\left(50 \mathrm{MHz}\right.$, Acetone-d $\left.{ }_{6}\right) \delta(\mathrm{ppm}) 84.90(\mathrm{~d}, J$ $=163.5 \mathrm{~Hz}), 128.80(\mathrm{~d}, J=6.5 \mathrm{~Hz}), 138.13(\mathrm{~d}, J=20 \mathrm{~Hz})$. (c) $1,4-$ Bis(bromofluoromethyl)benzene (4). $R_{f} 0.20 \quad\left(\mathrm{SiO}_{2}\right.$, Hexane $100 \%) .{ }^{1} \mathrm{H}-\mathrm{NMR}(200 \mathrm{MHz}$, Acetone-d 6 ) $\delta(\mathrm{ppm}) 7.86$ (d, 2H, $J=$ $48 \mathrm{~Hz}), 7.72(\mathrm{~s}, 4 \mathrm{H}) .{ }^{13} \mathrm{C}-\mathrm{NMR}\left(50 \mathrm{MHz}\right.$, Acetone- $\left.\mathrm{d}_{6}\right) \delta(\mathrm{ppm})$ 92.74 (d, $J=249.5 \mathrm{~Hz}), 126.63$ (d, $J=6.5 \mathrm{~Hz}), 141.94$ (d, $J=20$ $\mathrm{Hz})$. (d) Dimethyloctylsilyl-p-xylene (7). $R_{f} 0.36\left(\mathrm{SiO}_{2}\right.$, Hexane 100\%). ${ }^{1} \mathrm{H}-\mathrm{NMR}\left(200 \mathrm{MHz}, \mathrm{CDCl}_{3}\right) \delta(\mathrm{ppm}) 7.28(\mathrm{~s}, 1 \mathrm{H}), 7.09$ (s, $2 \mathrm{H}), 2.43(\mathrm{~s}, 3 \mathrm{H}), 1.41-1.14(\mathrm{~m}, 12 \mathrm{H}), 0.97-0.75(\mathrm{~m}, 5 \mathrm{H}), 0.33(\mathrm{~s}$, $6 \mathrm{H})$. (e) 2-Dimethyloctylsilyl-1,4-bis(bromomethyl) benzene (8). $R_{f} 0.32\left(\mathrm{SiO}_{2}\right.$, Hexane 100\%). ${ }^{1} \mathrm{H}-\mathrm{NMR}\left(200 \mathrm{MHz}, \mathrm{CDCl}_{3}\right) \delta$ (ppm) $7.48(\mathrm{~s}, 1 \mathrm{H}), 7.43$ (s, 2H), $4.61(\mathrm{~s}, 2 \mathrm{H}), 4.48(\mathrm{~s}, 2 \mathrm{H}), 1.43-$ $1.19(\mathrm{~m}, 12 \mathrm{H}), 0.99-0.88(\mathrm{~m}, 5 \mathrm{H}), 0.42(\mathrm{~s}, 6 \mathrm{H})$. 